\title{
Agosto: lo histórico dentro de la ficción ${ }^{1}$
}

\author{
Susan Peñuela Rodríguez \\ Licenciada en Lenguas Extranjeras de la Universidad del Valle \\ Universidad del Valle, Cali, Colombia \\ https://orcid.org/0000-0002-9442-1070 \\ suerochan@hotmail.com
}

\section{Resumen}

La novela brasilera Agosto, escrita por Rubem Fonseca en el año 1990 relata los sucesos histórico-políticos que se desarrollaron tras el suicidio del presidente Getulio Vargas, quien dirigió el país desde 1950 hasta 1954. Esta obra une la novela policíaca y la novela histórica, dando como resultado una hibridación entre las dos. En el presente artículo se realiza un análisis sobre los hechos históricos que trata la novela, dejando de lado la trama ficticia que se desenvuelve en relato policíaco y centrándose en lo que aconteció dentro del contexto histórico del Brasil.

Palabras clave: Contexto histórico; Getulio Vargas; novela brasilera; novela histórica.

\section{Hbstract}

The Brazilian novel August, written by Rubem Fonseca in 1990, recounts the historical-political events that developed after the suicide of President Getulio Vargas, who led the country from 1950 to 1954. This work unites the police novel and the historical novel, resulting in a hybridization between the two. This article analyzes the historical facts that the novel deals with, leaving aside the fictitious plot that unfolds in a police story and focusing on what happened within the historical context of Brazil.

Keywords: Brazilian novel; Getulio Vargas; historical context; historical novel.

\author{
Recibido: 17 de agosto del 2019 \\ Reflexión \\ https://doi.org/10.25100/poligramas.v0i50.10514
}

\section{¿Cómo citar este documento en MLH? - How to quote this document in MLA?}

Peñuela, Susan. "Agosto: lo histórico dentro de la ficción." Poligramas 50 (2020): n. pag. Web. Fecha de acceso (día, mes en mayúscula y abreviado, y año).

\footnotetext{
1 Procedencia de la reflexión: Este documento hace parte de la investigación del trabajo de maestría.
} 
History, Stephen said, is a nightmare from which I am trying to awake. James Joyce, Ulyses

La novela se desarrolla dentro de un contexto histórico en el cual se narran los últimos 24 días del presidente Getulio Dornelles Vargas antes de su suicidio. A la par con este desenlace se desarrolla una narración ficcional en la que un detective está tras la pista de un crimen en el que están involucrados políticos y empresarios importantes del gobierno. Tanto en la narración de Getulio Vargas como en la del detective Alberto Mattos se describen hechos reales del Brasil y de lo que aconteció dentro de esa época.

Agosto cumple una función de novela histórica, aunque toda novela es en sí misma una narración de un proceso del pasado, como lo afirma Baumgarten:

Toda novela, como producto de un acto de escritura, es siempre histórica, por lo tanto, reveladora de, por lo menos, un tiempo al que podríamos llamar tiempo de escritura o de la producción del texto. Sin embargo, tal definición, por más verdadera que pueda ser, no sirve para lo que comúnmente llamamos novela histórica dentro de los estudios literarios (68)

Es por esto mismo que la novela cumple con el propósito de mostrar un determinado contexto histórico; en este caso el del suicidio de Getulio Vargas y los hechos reales que se entrelazan dentro del personaje ficcional Alberto Mattos, para resaltar esta fase de la vida de Getulio Vargas. Como lo menciona Baumgarten, "En este ámbito, novela histórica corresponde a aquellas experiencias que tienen como objetivo explícito la intención de promover una apropiación de hechos históricos definidores de una fase de la historia de determinada comunidad" (68). Esta comunidad podría no solo ser la brasilera, sino también el resto de la comunidad latinoamericana.

Los inicios de la novela histórica se remontan desde el siglo XIX con la producción literaria de Walter Scott, más precisamente terminando la época del romanticismo. Durante este periodo se definieron conceptos nacionales como los europeos y americanos, tal como lo afirma Baumgarten "la novela histórica desempeñó un importante papel en la construcción de las identidades/nacionalidades que anhelaban afirmarse en las diferencias" (68). En el caso Latinoamericano, los principios de la novela histórica empezaron en la época de los 70 con la necesidad de narrar los discursos que marcaron la construcción de las diferentes naciones.

Como se cita en el texto de Baumgarten, "En| el caso brasileño, podemos afirmar que después de los años 70 asistimos a la aparición de un gran número de novelas volcadas a la 
recuperación y la escritura de la historia nacional" (68), que es revisitada en sus diferentes momentos. La lectura del conjunto de esa producción revela, por lo menos, la existencia de dos caminos, preferiblemente se enfocará en uno en especial en el cual se sitúan las narraciones que focalizan acontecimientos que integran la historia oficial y definen la propia constitución física de las fronteras brasileñas, como lo es Agosto.

Por lo anterior, Agosto cumple las características de una novela histórica. Como lo menciona Lukasz: "Los acontecimientos narrados en la novela están organizados observando la cronología temporal" (citado en Baumgarten 69). Los 24 primeros capítulos narran los últimos días de Getulio Vargas y además de esto, "se vale de personajes ficticios, puramente inventados, en el análisis de los acontecimientos históricos" (Baumgarten 69). En este caso, el detective Mattos se entrelaza como personaje ficticio para servir en la narración de gran parte de la historia, siendo él quien presenta y descubre los hechos, dado que "las personalidades históricas, cuando están presentes apenas son citadas o integran el telón de fondo de las narraciones" (69).

Getulio Vargas, como su hija Alzira (la cual cumple un papel importante dentro de la narrativa), son apenas citados en pequeños diálogos, aunque el mandatario es mencionado dentro de toda la historia, lo que concuerda con el autor cuando expone que "los datos y detalles históricos tienen la finalidad de conferir veracidad a la narración, aspecto que vuelve indiscutible a la historia" (Lukasz 69), generando mayor credibilidad en el lector. Además de esto, y por medio del discurso de la historia es que el narrador logra contar los hechos desde el uso de la tercera persona en su discurso, como se evidencia en le novela Agosto cuando se describen las charlas de los militares, la fuerza aérea, el contexto histórico de la novela, la Fundación Getulio Vargas, la supuesta carta testamento, los partidos políticos, el atentado contra el periodista y lo acontecido al candidato presidencial Lacerda. Es decir, en la novela hay un narrador en tercera persona que se caracteriza por contar los hechos históricos y ficcionales con bastante detenimiento, además de presentar su gran conocimiento de detalles muy personales de los personajes históricos.

\section{La importancia del punto histórico en la novela}

La novela presenta puntos históricos reales y los narra dentro de un contexto real, los últimos 24 días del presidente representados en los 24 capítulos. Estos puntos históricos pueden ser recopilaciones de personas cercanas del presidente, "testimonios que de la misma manera tienen igual validez histórica, una validez desde un punto de vista objetivo" (Carr 10). Estos son un cuerpo de hechos que se encuentran dentro de la narrativa de la historia por medio de los testigos 
que la presenciaron, en este caso, la hija del presidente: Alcira Vargas de Peixoto. Los hechos que ella narra son de los que fue testigo en los últimos días del mandatario; esto, en palabras de C. P. Scott, sería "Los hechos son sagrados, la opinión libre" (citado en Carr 13), lo que significa que la opinión de ella, dentro de la historia, es válida aun siendo su familiar.

\section{¿Qué es un hecho histórico?}

Es en este caso, lo que aconteció en la vida de Getulio Vargas en sus últimos días como presidente de la republica del Brasil. Lo es también los acontecimientos que se narran en la novela con respecto a la historia convulsa del Brasil y los sistemas de corrupción que se develan en la misma. Es de igual forma la perspectiva de la hija del presidente al narrar lo que ocurre en sus últimos momentos. Como lo describe Carr, un hecho histórico es: "La creencia en un núcleo óseo de hechos históricos existentes objetivamente y con independencia de la interpretación del historiador es una falacia absurda, pero dificilísima de desarraigar" (16). Es, en conclusión, todo el tejido de la novela ya que el mismo cumple una función a la hora de recontar lo sucedido.

La novela es un rompecabezas gigantesco en el que se develan diferentes trozos, cada personaje cumple la función de unirlos y re-narrarlos. La historia se ve desde diferentes perspectivas y cada una de ellas cumple un propósito en común; lo más sorprendente es que tanto los personajes ficticios como los reales narran los acontecimientos desde sus miradas, tal como dice Carr "La imagen histórica tiene una propia óptica" (8). "La historia que leemos", escribe el profesor Barraclough, medievalista a su vez, "aunque basada en los hechos, no es, en puridad, en absoluto fáctica, sino más bien una serie de juicios admitidos" (citado en Carr 19), es decir que la historia no es sólo una serie de hechos medidos por fechas, sino que además es una narración de acontecimientos por medio de testimonios.

El narrador en la historia debe realizar la tarea de descubrir los hechos históricos por medio de las diferentes voces, "y descartar los muchos datos carentes de importancia por ahistóricos" (Carr 20). Es por este motivo que el escuchar otras voces puede ser un hecho histórico con mayor veracidad, como refiere Carr, "En 1910 el historiador norteamericano Becker afirmaba, con lenguaje deliberadamente provocador, que los hechos de la historia no existen para ningún historiador hasta que él los crea" (28).

El documento que conlleva a la parte histórica son los testimonios de los diferentes personajes, teniendo en cuenta que incluso los personajes ficticios logran describir lo que aconteció en la época. Como se menciona en el texto de Carr, no hay documento que pueda dar una constancia exacta de lo que ocurría en el momento histórico en el que se desarrollan los 
hechos, por lo que se deben hacer observaciones frente a los testimonios recopilados a lo largo del tiempo. Por este motivo, es importante que al narrar la historia se tenga en cuenta la naturaleza de la misma, como afirma Becker: "historiadores han reflexionado poco acerca de la naturaleza de las cosas y aun acerca de la naturaleza de su propia materia de estudio" (citado en Carr 26), de esta manera sino se comprende el contexto sociohistórico de los hechos que se están narrando, muy difícilmente se podrá entender la veracidad e impacto de los acontecimientos.

Toda historia es historia contemporánea. Esto quiere decir que la historia se ve con los ojos del presente y a la vez de los problemas de ahora o la continuidad de los mismos, ya que la tarea primordial del historiador no es recoger datos sino valorar; porque si no valora, “¿Cómo puede saber lo que se merece ser recogido?" (Carr 26). La reconstrucción del pasado en la mente del historiador se apoya en la evidencia empírica, no en una enumeración de datos. En la novela la reconstrucción de los hechos es lo que la hace histórica, reescribirlos es la manera de recordar el acontecimiento y rememorarlo. Por lo que se cumple lo que dice Carr: "En general puede decirse que el historiador encontrará la clase de hechos que busca. Historia significa interpretar" (32). La segunda observación es aquella más familiar para la necesidad en común, "por parte del historiador, de una compresión imaginativa de las mentes de las personas que le ocupan, del pensamiento subyacente a sus actos, lo que se denomina como comprensión imaginativa" (32). El historiador, en este caso Alzira Vargas, podría considerarse como el autor de la novela, pero en realidad es una de las narradoras de la misma, es la que estuvo en contacto con el presidente y todo lo que concernía con él, por lo tanto, trae toda la memoria del mismo en la novela, y es esta la que persiste en el presente.

La función de la narradora, en este caso, es el de traer ese momento trágico de la vida política del Brasil al presente y tratar de comprender por qué se trae de la memoria al momento actual. En ese instante es cuando el lector hace su interpretación, lo que está directamente ligado a lo planteado por Carr cuando expresa que "la función del historiador no es ni amar el pasado ni emanciparse de él, sino dominarlo y comprenderlo, como clave para la compresión del presente" (34).

El punto ideal es que la novela no solo sea de reconstrucción monótona de los hechos de los últimos 24 días, del suicidio del presidente, sino que se logre una interpretación más acertada de los mismos. Que el historiador, quien es en este caso la narradora y testigo de los acontecimientos, Alzira Vargas, pueda demostrar cómo fue ese momento sin distracciones históricas. Por esto, se ve la historia como una "compilación objetiva de los hechos (...) La historia como producto subjetivo de la mente del luchador quien fija los hechos históricos y los 
domina merced al proceso de interpretación" (Carr 39). Reafirmando la necesidad de los hechos y la relación que tienen con el historiador y con el presente en el que vive, Carr expresa que:

El historiador y los hechos de la historia sí son mutuamente necesarios. Sin sus hechos el historiador carece de raíces y es; los hechos, sin el historiador, muertos y falsos de sentido. Mi primera contestación a la pregunta de qué es la historia, será pues la siguiente: un proceso continuo de interacción entre el historiador y sus hechos, un de algo sin fin entre el presente y el pasado. Así, el historiador comienza con la selección provisional de los hechos, y una interpretación provisional a la luz de la cual esa selección ha sido hecha, tanto por otros como por él mismo. (40).

En este caso desde el Brasil como colonia, el Brasil como productor agrícola, el Brasil cómo república, el Brasil como dictadura, el Brasil del partido de los trabajadores y, por último, el Brasil de Jair Bolsonaro.

\section{El contexto histórico de Brasil}

El Brasil es un país extenso, cuenta aproximadamente con 8.511.189 kilómetros cuadrados. Además, cuenta con características propias de su extensión: "cadenas de montañas, las barreras forestales, los ríos de 'media agua' la extensión del territorio, el desierto seco y el propio elemento indígena" (Montalvo 21). Aun así, la geografía brasileña jugó un papel negativo en la unificación del Brasil, y hasta que la misma no dejase de ser un impedimento, el Brasil no podría crecer como una nación con una sola visión (21).

Los ríos fueron la fuente de unión entre las diferentes regiones. Fueron además la solución a la separación geográfica y la separación entre bandeirantes y paulistas. El río San Francisco y el Amazonas facilitaron el comercio interno; cabe decir que el rio San Francisco también atraviesa Minas Gerais, Bahía, Sergipe y Pernambuco. Es por esta fuente fluvial que se facilitó el dominio y el control de la colonización del Brasil, afectando positivamente en la riviera el cultivo de caña de azúcar (Montalvo 35).

La sierra del mar. En el litoral se instalaron las poblaciones agricultoras. En el sertón se instalaron las poblaciones ganaderas creando grupos como los bandeirantes y los pastores del altiplano. En la costa se instalaron los ingenios de caña de azúcar, los cultivos extensivos de tabaco, de caña, maíz, estableciendo una civilización en todo diferente a aquella que los mineros y paulistas formaban paralelamente (Montalvo 35). 
El bandeirante formó parte de la construcción del país, pero como prócer latifundista. Él mismo generó progreso económico en la época, pero su papel también tuvo matices negativos ya que el bandeirante fue un producto de la colonia.

\section{Ciclos Económicos del Brasil Colonia}

El ciclo de Palo Brasil se interpretó como el ciclo del trueque comercial. Los europeos traían ropas, utensilios de hierro para el trabajo, objetos domésticos de loza, collares, rosarios, espejos, baratijas, etc. En cambio, recibían adornos artísticos, objetos de cerámica de caza, monos, entre otros. "Los colonizadores implementaron los hábitos de los nativos: la red para dormir, la piroga para navegar, etc. El mameluco (o colonizador) ya no era más un extranjero, se hizo parte del Brasil y comercializó el Palo Brasil en Europa con gran éxito" (Montalvo 43). En concordancia con lo anterior: "él mismo fue el elemento 'colonizador nacional'. Este era el futuro 'Bandeirante', el factor más importante de la conciliación colonial, pertenece sin duda, al papel preponderante en el llamado ciclo del Palo Brasil" (44).

\section{Litoral y Sertón}

Mameluco inicia en Brasil la colonización agraria del litoral plantando la caña y contribuyendo a la monocultura agraria, la misma que trajo consigo la mano de obra de esclavos negros africanos en el sertón. En este último nacía el corral o centro económico de la civilización pastoril y punto de encuentro de diferentes corrientes migratorias (Montalvo 48).

\section{El litoral, el ciclo del azúcar}

Palo Brasil cae en el siglo XVI y empieza la era del azúcar gracias al establecimiento de cultivos de caña en Pernambuco y Bahía, creando así el latifundio agrícola (Montalvo 41). La caña se trae desde Cabo Verde hasta Brasil encontrando en este país un clima propicio para su siembra adecuada, así "el cultivo de azúcar se convierte en el primer producto de exportación del Brasil" (Montalvo 50). Él mismo eleva su precio en el mercado y hace que se generen nuevos "Señores de Ingenio", convirtiendo a Pernambuco en un emporio azucarero mundial (51). Pero esta bonanza azucarera solo trajo consigo desigualdad en la repartición de riquezas: "la llave del problema social del cielo azucarero está seguramente en esta antinomia: casa grande y sensala. Indudablemente ninguna civilización brasileña tuvo mayor esplendor y mayor miseria, menos 
equilibrio en el reparto de la riqueza, más violencias, más errores, que en la civilización nacida del azúcar" (52).

\section{El sertón, el ciclo del cuero}

Hacia el oeste, extendía el sertón interdicto a los colonizadores por el tratado de Tordecillas y por la áspera defensa de los indígenas que, huyendo de la conquista portuguesa, se habían refugiado en la selva (Montalvo 53). El sertón tuvo un papel decisivo en la formación de la unidad del Brasil: la vía de ganado y el rio San Francisco o el Rio de los corrales. Las poblaciones del Sertón estaban conformadas por bahianos, paulistas, mineros, criadores de ganado, buscadores de piedras preciosas, garimparios y todos fueron participes del "ciclo de cuero" o "ciclo de la cría de ganado". Esta Era del cuero es la etapa en la que se empieza a formar una identidad de unidad nacional y el desarrollo económico social brasileño: es la etapa nacional de su historia (Montalvo 54).

El Rio minero es donde los bahianos y los paulistas establecieron la industria del ganado. Más de medio millón de cabezas pertenecían a las Fazendas bahianas, la cual se extendía desde el marañón, sertones, Rio Grande del Norte, Parahiba, Pernambuco y hasta las poblaciones de la zona central de Bahía y el norte de Minas Gerais. "El ganado demandaba poca gente para su cuidado, proveía su alimentación y se pagaba muy bien" (Montalvo 56); este provocó el surgimiento de los Bangues (pequeños curtanas), los cuales se asentaron en diversos puntos del territorio: Curitiba, Santa Catalina, Campiñas gauchas, Marajo, San Pablo, en todo el territorio brasileño. Ningún otro ciclo, como el del cuero, tuvo mayor extensión y significado en el establecimiento de las posesiones de todo el país, en la unión de diferentes actores (Montalvo 57).

\section{El sud- El ciclo de la caza al indio y el ciclo de la minería}

El Bandeirante era el terrateniente del Brasil, entre 300 a 400 hombres que conocían muy bien los terrenos y entre la selva y las zonas de difícil acceso perseguían a los indígenas para convertirlos en esclavos. Es por esto que "los grupos de Bandeiras fueron los que generaron la expansión colonizadora y la consolidación del espíritu nacional" (Montalvo 54). Esto produjo enfrentamientos entre las comunidades indígenas y los mamelucos, y con estos, el aniquilamiento casi total de esta población vulnerable. Por esto, "al aniquilar la población indígena se produce el ensanchamiento de la frontera con el retroceso forzado del límite de Tordecillas" (60). Además de esto, "Los bandeirantes se esparcieron por todo Brasil, a su paso se hicieron a tierras, criaron ganado y fundaron villorrios, los cuales serían las futuras ciudades brasileñas" (61), que están 
cimentadas en tierras tomadas por la fuerza a los indígenas. Es así como el bandeirantismo se convierte en el elemento más fuerte de colonización y de la población.

Después del auge del bandeirantismo, se genera un nuevo movimiento que es el monocultivo del café. Con este se promueve además el auge de las minas de oro y el mestizaje entre portugueses, indios y negros. Durante la época del monocultivo del café y la explotación minera se integran los paulistas, emboabas, sertonistas, habitantes del litoral empobraidos, entre otros grupos, en busca del enriquecimiento y la fortuna. Asimismo, se genera la integración del centro del Brasil facilitando la unión de las diferentes zonas del país; también empieza la centralización administrativa en Rio de Janeiro como capital portuaria del país. Es por esta zona portuaria que salían las riquezas hacia la corona de Portugal, provocando el enojo de las poblaciones mineras que empezaron a sentirse explotas a manos de la corona. Es también por esto que, con el ciclo de la minería, nace el sentimiento de la indecencia de la corona portuguesa, de forma que surgen malestares hacia ella y "los que propician la primera lucha son los emboabas en contra del cobro de las quintas $2 "$, al ser ellos los que menos recompensas recibían, sintiéndose como los más explotados (Montalvo 66).

\section{Ciclos económicos de Brasil Imperio El ciclo del café}

El café se consolida como el monocultivo de mayor rentabilidad del país en 1852 gracias también a la mano de obra esclava negra. De aquí surgen las "fazendas" como consecuencia de la tala de selva con el fin de propiciar el crecimiento poblacional, generando también vías férreas como "La Magiana, La Sorocabana y la San Paulo Ralway y ligando la capital de la provincia al puerto del Mar, Santos y otros puntos de concentración cafetera" (Montalvo 74). Asimismo, Sao Paulo fue el epicentro del comercio cafetero gracias a su cercanía al mar y las cuatro vías principales que lo conectaban con el resto del país. Por esto, "el monocultivo cafetero generó riqueza y prosperidad para algunos sectores del país, hasta que llegó el crack de 1929 de New York y produjo pérdidas significativas en los mercados internacionales, incluyendo Sao Paulo" (79).

Los inmigrantes llegaron a estos cultivos y junto con ellos las nuevas políticas liberales de abolición de la esclavitud. En su tiempo, Brasil fue uno de los países que más inmigrantes recibió y cuando se vieron obligados a abolir la esclavitud, se pusieron en la tarea de utilizar a los inmigrantes como trabajadores de bajo costo, llegando incluso a explotarlos, con el fin de hacer crecer su propia economía.

\footnotetext{
${ }^{2}$ Las quintas son el impuesto que debían pagar las comunidades indígenas.
} 


\section{Las Campañas Nacionales}

La esclavitud fue un factor determinante para la formación del país. Sin la mano de obra negra los cultivos de caña, luego de café y la explotación de las minas no hubiera sido posible. En este sentido Montalvo expone que "la influencia social de los negros esclavos, y la extensión de su cruza, fueron más pronunciadas en Brasil que en cualquier otra nación de América" (88). Por lo tanto, es gracias a la esclavitud que se crean los grandes monocultivos y emporios brasileros, y es esta misma la que al mezclarse con el resto de la población de colonizadores genera la unión nacional.

En el momento en que se presenta la abolición de la esclavitud, las dinámicas en Brasil se ven obligadas a cambiar (Montalvo 83). Primero, en 1850 se vota la ley Eusebio de Queiroz, que termina definitivamente con el tráfico negrero. Tras esto, en 1883, las ciudades de Ceara, Amazonas y Rio Grande del Sud ponen en libertad a todos sus esclavos. Finalmente, en 1888, la princesa Isabel firma la ley áurea, que libera definitivamente a todos los esclavos del país.

Después de la abolición de la esclavitud surge la proclamación de la república y con ella el reforzamiento de la propaganda política, donde, según Montalvo, "intervinieron en ella los mismos nombres que se habían destacado como ardientes abolicionistas" (95). A su vez, "Sao Pablo, el mayor centro abolicionista, fue también el mayor centro de propaganda republicana" (95). De esta forma, la idea de la república en el Brasil se vio influenciada por la corriente positivista que a su vez tuvo un gran impacto en la estructura política por causa de la propaganda republicana, causando que el ejército fuera, a su vez, abolicionista y republicano.

La industria fue la promotora de la unión brasilera, impulsó la movilización rural hacia la parte urbana y generó la comunicación entre los diferentes puntos del Brasil. Como afirma Montalvo, "las vías férreas comunicaron los diferentes puntos del Brasil, atrayendo a los rurales a las grandes ciudades intensificando el espíritu nacional y preparando al país con el plan de coordinación de líneas de comunicación" (15). Además de esto, la industria pasó de ser una colonia a un Estado republicano gracias a "la instalación de la alta siderurgia, de la creación de la industria petrolífera, del equipamiento de las fuerzas armadas de desarrollo de la policultura agrícola" (15).

\section{Getulio Vargas}

Nacido en Sao Borja, Rio Grande do Sur, el 19 de abril de 1882, es hijo de Manuel do Nascimiento Vargas y Candida Dornelles Vargas; originario, él, del estado de Sao Paulo y perteneciente a las 
familias paulistas antiguas (Montalvo 110), Getulio Dornelles Vargas fue un político de procedencia gaucha con raíces paulistas. Por su parte, Montalvo lo describe como "un hombre frio, sereno ante el peligro y comprensivo ante los dolores humanos en su situación de centinela" (110).

En sus primeros años prestó servicio militar, el cual contribuyó a su carácter disciplinado y a su vida pública. A los 25 años se convierte en diputado y empieza su trayectoria política distinguiéndose entre los demás y siguiendo las tradiciones castilhista de su familia. Es en esta misma época en que el positivismo incursionó en el ejército junto con la propaganda republicana, empezó una época "comtista" basada en las ideologías de Augusto Comte, Benjamin Constant, Hermes de Fonseca y Quintino Bocayuna (Montalvo 114). De esta manera empieza su construcción de gobierno para el Brasil de la era: "El Estado Nuevo". Getulio Vargas no se limita solo a sus obras públicas, sino que además incentiva a la formación de la unidad brasileña:

(...) que la comunidad y la lengua de la tradición de las costumbres y de la literatura con el auxilio de la selección histórica, no se detenga, y que el alma del futuro entienda a la del pasado (...) Es preciso crear de la civilización material, una civilización intelectual, con la contribución de todos los elementos, para que estos aprendan a estimar las tradiciones, a amar y defender el régimen (Montalvo 118).

Aunque es en esta época como diputado que por motivos de fraude electoral en el municipio de Lachueira se ve obligado, por el partido republicano de San Borja, a renunciar a su cargo generando su primer impase político. En 1923 el ámbito político gaucho se agita nuevamente y Borges de Medeiros, candidato del mismo, se presenta por quinta vez, pero una aplastante victoria derrota al candidato republicano y deja en primer lugar a su oponente. El Federalista Getulio Vargas decide apoyar al candidato republicano recalcando la importancia que tiene el Estado de Rio Grande del Sud como Estado más joven de la Federación: "su discurso inicial es un documento vivo del espíritu de realidad anticipándose a toda una generación de políticos rio grandenses aprisionada en el molde del liberalismo abstracto, teniendo a la demagogia política y divorciada de la realidad económica" (Montalvo 123).

De esta manera, Getulio Vargas avanza en la política y el partido opositor empieza a debilitarse frente a su contrincante dando paso a la nueva era o mejor a "la revolución política". En 1930 se presenta el nacimiento revolucionario que lleva como nombre el mismo año, a la par lleva el descontento de las malas políticas del principal producto del país: el café. Con esto Montalvo afirma que la desorganización económica trae consigo una serie de factores 
descentralizados como lo es "la intervención al Estado nordestino de Parahiba, donde bandas facciosas armadas por el gobierno promocionan desórdenes públicos" (131). Al ser estos conflictos de interés, Getulio Vargas toma la iniciativa de unirse a uno de los bandos y proponer la centralización política para dar fin al conflicto de interés.

Es en este punto de quiebre que Getulio Vargas se presenta como candidato del Estado de Minas Gerais, después de que su antiguo presidente, Antonio Carlos, rompiera con el gobierno central, mostrando a Getulio Vargas como el candidato del pueblo en contra del oficialismo, por esto, inicia en 1930 una política centrada en reformar aspectos como: "Amnistía, leyes sociales, reforma financiera, lucha en contra de la seguire, incentivo a el área pecuaria, solución al dilema de la producción agrícola y nunca incorporar una sola política para el café" (Montalvo 132), los cuales velarían por las necesidades del pueblo en este momento histórico.

Dentro de esta reforma política y económica, Getulio Vargas también incluye como beneficiario al ejército y a la asamblea, colocando a estos en igualdad de responsabilidades y en conjunto con el crecimiento económico del país. De esta forma, se establece producir barato, el mejor número aconsejable de productos para abastecer el mercado interno fortaleciendo la producción pecuaria. En 1934 Getulio Vargas es elegido presidente y es en este mismo año, bajo su mandato, que se realiza el cambio de la constitución política en la cual se cita "la proclamación de la república, la centralización política y federalización administrativa. Las provincias se transformaron en Estados y la red administrativa pasó de las riendas de un emprendedor a las de un presidente" (Montalvo 157).

La renovación de la constitución no fue suficiente para evitar el recrudecimiento de las divisiones regionales y el enfrentamiento de los bandos de derecha e izquierda. Es en esta coyuntura donde surge el "Estado Nuevo" como etapa preparatoria del Brasil para la descentralización económica y la unificación política. Como se puede evidenciar en el texto de Montalvo: "Durante esta etapa el país se preparará de hecho para un régimen democrático: coordinado las líneas férreas del país, instalando la gran siderurgia, distanciando a las fuerzas armadas del equipo eficiente, y manteniendo la forma democrática" (160).

El propósito principal del Estado Nuevo fue el de dar un sentido nacional de federación, con la centralización política y la autonomía administrativa entre regiones, ya que el Brasil no tuvo una transición apropiada desde la colonia: Brasil-reino al Brasil-imperio y luego Brasil-república. Es sobre estas carencias de transiciones que los republicanos decidieron convertir las antiguas provincias en Estados sin considerar sus contextos históricos. 
Es en este contexto en el que el ejército brasileño desempeña un papel importante y del que Getulio Vargas tiene uno de sus mejores colaboradores y modernizadores (Montalvo 171). Por último, la crisis del 30 afectó profundamente la economía del café del país y es por este motivo que el gobierno decide cambiar de la monocultura a la policultura y liquida la política proteccionista del café como único producto posible. Por esto, el país cambia hacia una industrialización creciente y hacia una nueva reforma agraria.

\section{Vargas y la reorganización de la vida rural (1930-1945)}

La figura de Getulio Vargas fue una de las más controversiales de la historia de la republica del Brasil. Según la economista Eli Diniz, "Una de sus contribuciones fue al cambio de la vida rural y agraria y del mismo país entre 1930-1945" (21). Así, Getulio Vargas reformó la política agraria ayudando a los campesinos que en esa época contaban con muy poca representación del Estado.

Dentro de los años 1930-1945, Getulio Vargas contribuyó a la reforma agraria del país y aún más a la reorganización y legitimización de los campesinos de la época. Aunque su figura en el gobierno provisional, que comenzó en 1930, fuera controversial, fue esta misma la que ayudó a que la reforma fuera un hecho, legitimando la mano de obra agrícola en las zonas rurales. Como menciona Welch, hay pruebas suficientes para mostrar que el régimen de Vargas trató de "organizar la vida rural" desde su gobierno provisional en 1930 hasta 1945, que fue más bien una dictadura. El resurgimiento del movimiento campesino en 1970 y 1980 ya había llamado la atención de los científicos sociales en Brasil ya que los campesinos recordaban "el tiempo de Getulio como un tiempo próspero". En la década de 1970, Doña María, una cortadora itinerante de caña de azúcar, le dijo al antropólogo Verna Stolke lo siguiente: "Dejó esas leyes de que los pobres no son días, que no se puede despedir a alguien sin pagar los daños" (citado en Welch 3), refiriéndose al legado de Getulio Vargas.

La economía del Brasil en la época se ralentiza y genera una pérdida de ingreso de la divisa al país, debido a la gran depresión de Estados Unidos. Urgen medidas de cambio y dentro de estas medidas está la reorganización del área rural, las políticas con los campesinos y los dueños de tierras.

Cuando Getulio Vargas ocupa en 1930 el cargo de la presidencia a la fuerza, impone la ley de reorganización económica y social de colaboración entre las clases y un gobierno moderno que controle la economía. Esto fue con el propósito de liberar a los caficultores de Sao Paulo de las repercusiones de la gran depresión de la producción, el costo y la comercialización del café (Welch 4). Es en esta época que Vargas se enfrenta con diversas dificultades que toman fuerza 
con la problemática internacional, los crecientes nacionalismos y el bajo ingreso de inmigrantes, por lo cual se incrementó aún más la falta de mano de obra en los cultivos de café.

Para lograr acuerdos, Vargas propone "despertar el interés por el trabajo duro e instalar el deseo por los campesinos de trabajar eficientemente" (Welch 5). Como describe Collor: "Dado que los sindicatos de trabajadores agrícolas prácticamente no existen, será esencial promover la formación de algunos de ellos en varios Estados" (citado en Welch 5). Collor explica que el sindicalismo corporativo sería el medio que ayudaría a la política agrícola de Brasil. En marzo, Vargas emite el Decreto 19770 que explicaba cómo el Ministerio de Trabajo, Industria y Comercio de Collor asumiría la responsabilidad de regular las condiciones de trabajo en el sector agrícola, comercial e industrial, al registrar asociaciones de empleadores y empleados en el estado local a nivel nacional, como agencias oficiales de asesoramiento.

La posible solución a las nuevas dificultades fue la unificación de los campesinos por medio de los sindicatos, aunque esto significó limitar la participación de extranjeros en el mismo. De los 251 sindicatos que fueron reconocidos, 6 pertenecían a la parte agrícola. Welch menciona que "la atención del gobierno a los trabajadores rurales estuvo motivada en parte por la preocupación y las perspectivas de los tenentes ${ }^{3 "}$ (6). Al dirigir la cuestión agraria en Brasil, el programa tenentes requería que los trabajadores de 'el lado del país' deberían recibir los mismos derechos y beneficios que los trabajadores urbanos. Además de las garantías y la validez de las que fueron merecedoras los campesinos agricultores promedio, los tenentes fueron también beneficiaros del programa "Social funtion" o función social que proponía la diversidad de políticas para los trabajadores rurales.

Aunque parecía que las políticas de Vargas en el campo estaban funcionando, en realidad el exceso de poder de los terratenientes causó algunos opositores como Lindolfo Collor, quien se iría en contra del mismo partido que anteriormente apoyaba. Según Welch, "En julio de 1932, desataron una guerra contra su régimen. La inevitable victoria del gobierno federal sobre el paulista y el prominente papel de tenentes en la defensa" (6). Esto ocasionó la caída de Vargas ante la fuerza militar y la restauración del gobierno constitucional. Vargas tuvo que pensar en la estabilidad de su gobierno y su duración en el mismo, por este motivo tuvo que reescribir la constitución acorde con el conflicto (Welch 7). La oligarquía empezó a tener conciencia de que la dependencia del 'monopolio de la tierra y el control de las elecciones' no podía continuar. En consecuencia, invirtieron en negocios urbanos e industrialización, como lo ilustra Welch

\footnotetext{
${ }^{3}$ Tenientes y otros oficiales militares, pensadores y burócratas más jóvenes que apoyaron a Vargas
} 
"anticiparon la inevitable transformación de la relación rural urbana y, por lo tanto, la necesidad de crear otros medios para prolongar su posición dominante" (7).

En realidad, la política para estos empezó a gestarse después de 1942 indicando el inicio del Estado Nuevo y el centro de discurso de su política. Gomes expresa que "en la afirmación de la ciudadanía expresada como derechos sociales, el régimen presionó a los terratenientes y plantadores para colaborar en el desarrollo de leyes para establecer derechos sociales a los campesinos y empleados rurales" (citado en Welch 9). Estas políticas permitirían a Vargas el reconocimiento dentro de los grupos fuertes (SNA) sociedad nacional agrícola y la sociedad rural brasileña (SRB).

\section{Getulio Vargas desde el 1 hasta el 24 de agosto de 1954}

La historia de la novela empieza desde el día 1 de agosto de 1954 y termina el día 24 del mismo año. En este transcurso se mencionan, dentro de la narración, varios hechos históricos del Brasil de esa época. Sería importante aclarar qué se define como hecho histórico y cómo este se revela en la novela. Como menciona Carr, "La historia consiste en un cuerpo de hechos verificados. Los hechos los encuentra el historiador en los documentos, en las inscripciones, etc., lo mismo que los pescados sobre el mostrador de una pescadería" (12). Los hechos históricos que se presentan en la novela son los de la agitación política que se está viviendo en el Brasil de la época y cómo los diferentes poderes hacen que esta agitación culmine en el último adiós del presidente Getulio Vargas.

Uno de los hechos históricos que menciona la novela es el partido político PTB (Partido Trabalhista Brasileño), uno de los partidos sindicalistas que el mismo presidente funda para luego convertirse en un adversario del mandatario y apoyar la destitución del mismo. Tal como señala Fonseca, "Fundado en 1945, fue el partido de las masas urbanas alrededor del cual se agrupó el movimiento populista" (45). Otro hecho histórico es el atentado contra el periodista Lacerda y cómo este mismo responsabiliza al presidente Getulio Vargas de la muerte del militar Vaz. Como se evidencia en el texto de Fonseca, "-Responsabilizo al presidente de la Republica por el atentado- dijo Lacerda a los oficiales de la Aviación que lo escuchaban en silencio -fue la impunidad del gobierno la que armó el brazo criminal" (102). Acrecentando la secuencia de actos en contra del mandatario, el brigadier Eduardo Gomes no pierde la oportunidad para hacer nuevamente su candidatura y poder hacer frente por tercera vez consecutiva a su aspiración como presidente de la republica del Brasil. Aunque en el pasado hubiera perdido ante la oposición de Getulio Vargas dos veces, como lo menciona la novela, "El brigadier fue candidato a la presidencia 
por la UDN, en 1946 y 1950. En las primeras elecciones perdió frente al general Gaspar Dutra, ministro de guerra de Vargas durante la dictadura. En las segundas, frente al propio Vargas" (121). Una victoria inesperada del ex dictador pero que le daría favoritismo al brigadier en la clase media del Brasil por su intervención el 5 de julio de 1922.

Más adelante, dentro de la narración, Vargas es reconocido como un dictador que durante sus campañas políticas dio duros golpes en contra de otros mandatarios que se encontraban en el poder. Como se menciona en la novela: "Ahora Getulio no tiene las condiciones para dar un golpe. Él no iba a dar ningún golpe. Observó Calaravalho por qué piensa usted que Getulio canceló el viaje de Bolivia para inaugurar la carretera Santa Cruz de la Sierra -Corumba?" (Fonseca 131).

El presidente fue uno de los primeros impeachment que se ejecutaron en el Brasil, por el contrario de otros políticos de su época, tan solo un mes antes de su muerte. Treinta y cinco diputados estuvieron en su contra en el palacio del Catete y aunque Vargas pudo cerrar el congreso, la muerte del mayor Vaz cambió el rumbo de la historia (Fonseca 133). Este acontecimiento avanza en la historia y encuentra su punto clave en la fuerza militar, que encuentra motivos suficientes para derrocar al presidente culpándolo del atentado en contra del periodista Lacerda. Como menciona Fonseca, "Los militares están furiosos con la muerte del mayor Vaz. Hoy será realizada una asamblea en el club de Aviación con objetivos nítidamente golpistas" (135). Con el propósito de mantener la llama encendida y el clima de indignación, los militares se reunieron con Víctor Freitas y altos militares para seguir las pistas que los policías abandonaban, ya que involucraban a políticos importantes y personas cercanas al mandatario. Uno de estos era Gregorio Fortunato, quien fue el jefe de seguridad presidencial de Getulio Vargas hasta la muerte del mismo en 1954. Fue asignado a este cargo por el mismo hermano del presidente, Benjamín Vargas, después del fracaso del Golpe Integralista contra el mandatario. Además, fue acusado abiertamente por el intento de asesinato contra el primer opositor de gobierno de Getulio Vargas, el periodista Lacerda, como menciona la novela: "Gregorio es el símbolo patente del sicariato con que Getulio Vargas, temeroso del pueblo, procura rodearse. Representa el método de hacer callar las voces que incomodan el sueño del gran oligarca, que quiere dormir sin pesadillas a pesar de sus crímenes" (151).

Otro involucrado dentro del atentado es Lutero Vargas, hijo del presidente, quien dentro del régimen de su padre en 1950 ocupó el cargo de diputado. Después del régimen y presidencia de su padre, fue reelegido como diputado del distrito federal, cargo que ocupó hasta el mandato de su padre. Fue además presidente del Partido Trabalhista brasilero (PTB), cargo que ocupó hasta 1960. Lutero Vargas fue opositor político del periodista Carlos Lacerda de la Unión 
Democrática Nacional (UDN) en las elecciones de la Cámara Federal en 1954. El día 5 de agosto del mismo año es acusado por el crimen "de la calle de Tonelero" en el cual fue abatido el mayor Vaz de la fuerza militar. Se vio envuelto en este crimen por el sicario contratado Alcino Joao do Nacimiento, el cual afirmó que fue Lutero Vargas el que lo contrató para cometer el delito. Como cita la novela: "Estás siendo acusado de instigador del crimen - dijo Vargas- Quiero oír de ti la afirmación de que eres inocente. Vargas observó detenidamente la fisonomía del hijo. Lutero nunca cumplió con las expectativas que Getulio depositó en él" (Fonseca 165).

La propaganda en contra del presidente aumentó por medio del diario La Tribuna, con comentarios como: "¿Por qué aquellos que protegen al presidente son llamados capangas y los que protegen a Lacerda son llamados amigos?" (Fonseca 211). Carlos Lacerda fue un periodista y político brasilero desde 1949, fue el fundador del periódico La Tribuna en el cual también trabajaba como columnista. Sus principios políticos fueron comunistas, para luego cambiarse al partido de la Unidad Nacional Democrática (UDN), conocido por su ideología conservadora. La habilidad de Lacerda como periodista le dio la fuerza suficiente para acaparar todo el favoritismo del pueblo.

Por su lado, Getulio Vargas fue un orador sin mucha fuerza y aun así el pueblo brasilero lo seguía. En cambio, Lacerda, con su capacidad de expresión y conocimientos de periodista, logró conmover aún más la audiencia brasilera, al utilizar en sus columnas comentarios como: "Despedazado. Emboscada cobarde. Mutilación salvaje. Degollado" (Fonseca 213). Lacerda conocía la fuerza de las palabras, "tuvo una buena escuela en el Partido Comunista, donde fue el joven líder de un grupo conocido como Socorro Rojo. Una interesante trayectoria: comunista sectario exaltado a santurrón reaccionario Udenista" (213). Lacerda hizo recordar al público brasilero los atentados que presuntamente se perpetraron por Getulio Vargas, "En enero de 1920, según la prensa, Getulio Vargas, con su cómplice Spriano Serra, habría asesinado al cacique Tiburico Fonque, de la tribu de los inhacora" (212), Además de este atentado, en 1923 Vargas es acusado de asesinar al ingeniero Ildefonso Soares Pinto, secretario de obras públicas del entonces gobernador Borges de Medeiro, en complicidad con Soriano Serra.

Aunque todo parecía en su contra, Getulio Vargas tuvo el respaldo de la fuerza militar, donde su familia también tuvo participación activa, como es el caso de su hijo Lutero Vargas en la Segunda Guerra Mundial. Históricamente, el 3 de noviembre de 1930 fue elegido presidente provisorio por la junta militar hasta el año de 1934. Durante este periodo anuló la constitución de 1891 y gobernó por decretos. Es a este periodo al que se refiere la novela al afirmar que "el Ejército, nunca le dio importancia a las ansiedades de la Aviación -replicó Vargas- Ni siquiera a 
las de la Marina, que es el arma más antigua y tradicional. ¡El Ejército es el Ejército!” (Fonseca 198).

Por otro lado, el café, como fuente principal económica, era un indicador de la problemática por la cual estaba atravesando el Brasil, tal como se menciona en el siguiente aparte del texto: "los mercados de cambio y de café abrieron en actitud de expectativa" (Fonseca 341). Por esto, la mayoría de los operadores todavía inseguros en cuanto a la resolución 99 de la Sumoc (Superintendencia de Moneda y de crédito), la cual establece la tasa fluctuante de cambio, los precios del dólar, del café y demás bienes, empezaron a variar en razón de la tasa de cambio libre, y "cuya media sería calculada por la bolsa del cambio del banco do Brasil" (341). Esto quiere decir que las ventas llegaron a conocimiento de otros comerciantes del café, los cuales se vieron afectados por el proteccionismo que el gobierno había ejercido sobre el precio de este y la falta de credibilidad en cuanto al cambio repentino del precio del mismo. En 1930 Getulio Vargas rompe con el pacto del "café con leche", y es por esto que manda a calcinar 71.068 .581 bolsas de café, una cantidad que hubiera podido atender a la demanda mundial de café durante al menos tres años (Anjos y Belik 4). Este incidente fue causa por la cual en "el año 1933 se creó el Departamento Nacional del Café (DNC), una división autónoma del gobierno central que hasta 1946 asumió el control de la economía cafetalera del país" (Anjos y Belik 4), generando nuevas políticas económicas hasta 1940. Lastimosamente, las políticas que el mandatario genera repercuten en el último año de su gobierno y más precisamente en sus últimos días ante la sospecha de un nuevo cambio de política para uno de los cultivos más importantes del Brasil.

Siguiendo con el propósito cronológico de la novela, la política del Estado Nuevo era restaurar la unidad nacional del país por medio de un partido político unificado. Este era el programa bandera de Vargas, como se cita en el texto Estado Novo no Brasil: "el paso de la hegemonía de los grupos políticos regionales -las "oligarquías"- para la supremacía de los partidos nacionales fue una operación larga y difícil" (Codato 305). Esta acción, que ocurrió entre 1930 y 1945, exigió integrar a los diversos grupos rivales de las clases dirigentes, con el propósito de garantizar al sistema político nacional tres cosas: "un grado razonable de cohesión interregional (unidad), apoyo continuo al presidente nacional (legitimidad) y equilibrio institucional (gobernabilidad)" (305). Con el Estado Nuevo, el presidente Vargas dio una nueva carta constitucional, reforzando el poder central, extendió su democracia hasta el sistema inexequible entre el voto universal, como lo menciona Fonseca: "la carta constitucional del 10 de noviembre de 1937 es un documento de alto valor histórico. Ella quedará para la posteridad como un símbolo de grandeza nacional" (353). 
En su contraparte, el partido udenista, creado en abril de 1945, del cual el periodista Lacerda era representante, fue un fuerte oponente de las políticas unificadoras y autoritarias del presidente Getulio Vargas, como se cita en el siguiente texto: "no podríamos dejar de resaltar también el hecho de que esa oposición udenista, que buscó durante toda su existencia identificarse con ideales políticos liberales, en contraposición a las prácticas autoritarias atribuidas a Vargas y sus aliados" (Biroli 87). A su vez, este partido recurrió desde 1945-1964 innumerables veces a deslegitimar el curso normal de las elecciones y, en última instancia, al golpe, en la medida en que las urnas no le abrían el camino para el poder gubernamental, especialmente para la Presidencia de la República. La UDN se organizó de manera que no pasaría un día sin que fuesen proferidos en la cámara y en el senado discursos contra Vargas (Agosto 2004).

Acto seguido, el Diputado Herbert Levy realizó su discurso en el que insinuaba el último adiós del Partido de los Trabajadores: "los hombres honestos, los ciudadanos impecables, como el incorrupto Carlos Lacerda, símbolo de lo mejor que el Brasil podía ofrecer en resistencia moral, eran amenazados por los asesinos protegidos por los dueños del poder" (Fonseca 354). De esta manera responsabilizaba al presidente de la república del atentado y aseguraba su ascenso al poder: "se sabía ya con certeza que el clima moral que hiciera posible un atentado como aquel que afrontaba la opinión publica había sido creado por el presidente de la República" (354).

Por consecuencia, el partido udenista se asocia con la marina y la aviación, aprovechan la oportunidad y los ánimos en contra del presidente para generar más presión sobre el mismo. El Coronel Adyl, acompañado de una escolta fuertemente armada, invade el Palacio del Catete con el propósito de apoderarse de toda la correspondencia privada y otros papeles del teniente Gregorio Fortunato, además de trescientos mil cruzeiros en efectivo (Agosto 2004). Dicha operación sería utilizada por la oposición en la cámara y el senado como prueba de que "el gobierno no gobernaba más" (Fonseca 359). Los udenistas no solo invaden el palacio del Catete sino que incitan a los diputados a pedir la renuncia del presidente: "Comandados por los udenistas, los diputados de la oposición iniciaron un coro que resonó fuerte en el recinto de la cámara: ¡Renuncia! ¡Renuncia! Renuncia!” (361). No fue la primera vez que el partido udenista intensificaba su campaña en contra de Getulio Vargas: en 1946, el partido UDN “intensificó los esfuerzos para cambiar el modelo de relaciones entre las potencias incluidas en La Constitución de 1946 a favor del Legislativo, teniendo como principal estrategia el cambio del sistema presidencial al parlamentario" (Mafort 106). 
La campaña parlamentaria tuvo un avance significativo pero lo no suficiente para tener una aprobación en el congreso. Mientras tanto, a finales de 1949, el gobernador de Sao Paulo, Aldemar Barros, selló la candidatura de Getulio Vargas formalizando el PTB (Partido de los Trabajadores del Brasil). No obstante, en 1954 la historia cambiará para este partido, ya una vez "desata la chispa de la revolución, quién más podría asegurar la vigencia de las instituciones" (Fonseca 361). En este sentido hubo una serie de acontecimientos que llevaron a la renuncia de la presidencia de Getulio Vargas, como se muestra a continuación:

En la cámara de diputados el líder de la mayoría, Capanema, constantemente interrumpido por los gritos de protesta de los diputados de la minoría, dijo que la renuncia del señor Getulio Vargas no era una exigencia del pueblo, era la exigencia de un partido político, del mismo partido político que intentó impedir su posesión con el célebre argumento de la mayoría absoluta, que quiso sacarlo del Catete hace poco tiempo con un impeachment sin fundamento, aquella exploración en torno de la muerte del mayor Vaz, era un paso más en la lucha iniciada hace cerca de cuatro años para conseguir que el presidente dejara el gobierno de cualquier manera, ya fuera por medio de la instigación popular, de la prensa o de las fuerzas Armadas (Fonseca 360).

No fue la única vez en la historia en la cual Getulio Vargas pudo ser dimitido como presidente de la república por medio de un impeachment, una política que nació en la constitución de 1891. Un ejemplo de esto es cuando en 1930, bajo la propuesta de "el café con leche" y la unión de diferentes partidos con el abanderado del Estado Nuevo, el partido PSD tuvo la oportunidad de hacerlo gracias a la influencia que ejercía sobre el congreso (Mafort 106). Por su parte, el Senado era la instancia política donde se emitía el juicio y condena si las partes producían un acuerdo de 2/3 de sus miembros. En una coyuntura en la que los partidos de Getulio Vargas, PSD y PTB, que apoyaron al gobierno del Estado Nuevo, poseían casi 2/3 de los miembros del Congreso, las posibilidades de un proceso de impeachment eran casi nulas.

La batalla en contra de Getulio Vargas no solo se limitó a la fuerza militar, también los medios de comunicación estuvieron involucrados, la UDN influyó en los militares mediante la presión de la opinión pública (Agosto 2004). Los grandes diarios apoyaron a la oposición, incluso el diario La última hora, que apoyó al presidente en el pasado, se abstuvo de mostrar su postura en los últimos momentos de la vida del mandatario, "-Getulio recibió hoy en la mañana a Assis Chateaubriand. Vamos a ver cómo se comportaban los periódicos de Chato de aquí en adelante. De todos modos, la batalla de la opinión pública está perdida para Getulio" (Fonseca 363). Ante 
la derrota electoral de 1950, los udenistas buscaron evitar que Getulio Vargas siguiera a cargo del mandato de cualquier manera posible (Matfort 109), anulando las elecciones ante la Corte Suprema Federal (STF) y movilizando a los militares para que intervinieran. Sin embargo, esto no fue exitoso porque se pasó a emplear los medios de comunicación como una forma de deslegitimar al mandatario y fortalecer los lazos con empresarios conservadores y militares que no simpatizaban con sus políticas (Mafort 109).

La petición de renuncia al presidente fue presentada en el club militar como una moción de exigencia, no sin antes también esclarecer el crimen del que se le acusaba, ya que posiblemente la investigación implicaría a Getulio Vargas como responsable del atentado en contra del periodista Lacerda. El ministro de Guerra interviene en medio del clima exaltado por los militares y llama a la calma, preocupado por no llevar el país a la anarquía y expresa que "en defensa de la constitución obraré con toda diligencia y vigor. Ese es mi papel y lo cumpliré hasta el fin" (Fonseca 395). La reacción del pueblo empezó desde el lanzamiento de los nuevos candidatos a la presidencia y por exigencia de más sectores del mismo a la renuncia del presidente. Lomagno, uno de los personajes clave de la trama, reflexiona sobre el momento convulso del país, la posible intervención de los militares con un golpe de estado, el fracaso del partido PTB, y sobre todo, las palabras que expresa su padre en el lecho de su muerte sobre el Brasil: "Hijo mío, no pienses que puedo cambiar al Brasil. Los franceses que son un pueblo inteligente, inventaron esta máxima perfecta, que entre más vieja más verdadera: 'Plus ça change, plus c'est la même chose'4" (414).

\section{Conclusiones}

Aunque por medio de la máxima francesa, otros autores como Gustavo Forero afirman que "El escritor establece en Agosto una teoría que podemos llamar de la necesaria continuidad del poder político conforme a las pautas de Getulio Vargas" (1), es decir que a pesar de los diferentes cambios democráticos del país, y el ataque constate de la fuerza militar a movimientos populares y comunistas, aún el Varguismo puede resurgir y permanecer en la política del país en nuestros días. Es importante tener en cuenta que Forero establece en su artículo el continuismo del Varguismo en el Brasil actual, pero más allá del Varguismo sin Vargas podría tenerse en cuenta que históricamente hubo también otras implicaciones que el autor Rubem Fonseca quiere resaltar dentro del relato histórico. Es también la razón de que determinado partido político surge con más fuerza que otro. Como afirma Montalvo, al desaparecer los movimientos libertadores, para manifestarse los partidos políticos y al desaparecer las luchas por la tierra, para aparecer la lucha

\footnotetext{
${ }^{4}$ Por más que se cambie, más queda la misma cosa.
} 
por el descontento del poder central, demuestra una vez más que no es el pueblo el que se levanta sino los partidos políticos. Esto con el propósito de que el movimiento conservador, el cual estaba atado a la economía de la agricultura y a 'la fórmula' donde el Brasil es visto como un país esencialmente agrario, perdiera su significación "a medida que las estadísticas demostraban el descenso de la economía agraria y el ascenso de la economía industrial" (Forero 13), retardando así el surgimiento del Brasil como país industrial por intereses personales y demostrando que el problema no solo fue político sino también económico.

Desde que el Brasil no fue más una colonia y empezó a ser una república, tuvo muy pocas transiciones y acuerdos económicos, los políticos conservadores mantenían aun la idea del latifundio, ya que eran parte también del poder agrario. Es por esto que "siempre en todas las revoluciones de la historia política del Brasil, los intereses económicos separan a los brasileños y los intereses políticos contra Portugal los unen" (Montalvo 14). Dentro de la novela es notorio que es la influencia de la economía industrial lo que separa a la nación brasileña y que a su vez los une en el espíritu de la nacionalidad fomentado en la máxima del Estado Nuevo de Getutlio Vargas y la consagración de todos los Estados Brasileños, o mejor dicho de todas las regiones que forman los Estados Federados. La economía del país encontraría su solución lógica en la industria, pero los intereses individuales devengaron en el fatídico 24 de agosto de 1954 con la futura renuncia y suicidio del presidente.

\section{Referencias}

Anjos, Flavio. Belik, Walter. Caldas, Nadia. "La caficultura en Brasil Evolución, situación actual y nuevos retos cara al futuro". Mundo Agrario 12. 23, (2011). Web 18 jul. 2019.

Baumgarten, Carlos A. "Aproximaciones a la nueva novela histórica brasileña". Contexto: Revista Anual de Estudios Literarios 14, (2008): 67-79. Web. 18 jul. 2019.

Biroli, Flavio. Jornalismo, Democracia e Golpe: A Crise de 1955 nas Páginas Do Correio Da Manha e de o Estado de S. Paulo. Revista. Sociol. Polít., Curitiba, 22. (2004) 8799, Web. 17 jul. 2019.

Carr, Edward H. ¿Qué es la historia?: Conferencias "George Macaulay Trevelyan" dictados en la Universidad de Cambridge en enero-marzo 1961. 10. ${ }^{a}$ ed. Barcelona: Seix Barral, 1981. Impreso.

Codato, Adriano. Estado Novo no Brasil: Um Estudo da Dinâmica das Elites Políticas Regionais em Contexto Autoritário. DADOS - Revista de Ciências Sociais, Rio de Janeiro. 58. 2 (2015) 305-330. Web. 17 jul. 2019. 
Diniz, Eli. Engenharia institucional e políticas públicas: dos conselhos técnicos às câmaras setoriais. In: PANDOLFI, Dulce (Org.) Repensando o Estado Novo. Rio de Janeiro: Ed. FGV. 21-38 (1999). Web 17 jul. 2019.

Fonseca, Rubem. Agosto. Bogotá: Editorial Norma, 2004. Impreso.

Forero, Gustavo. (2014). "Agosto, de Rubem Fonseca, y el Varguismo". Literatura y Lingüística 30 (2014): 1-22. Web. 18 jul. 2019.

Grutzmacher, Lukasz. "Las trampas del concepto 'la nueva novela histórica' y de la retórica de la historia postoficial". Acta Poética 27.1 (2006): 141-167. Web. 19 jul. 2019.

Mafort, Assis. "Reflections about the rules of the impeachment and its impacts on democracy: Brazil, United States of America and England in comparative perspective". Saúde Debate 40 (2016): 98-113. Web. 19 jul. 2019.

Montalvo, Ricardo. Getulio Vargas: Presidente de los Estados Unidos del Brasil y la unidad brasileña. Buenos Aires: M. Geiser, 1939. Impreso.

Welch, Clifford A. "Vargas and the reorganization of rural life in Brazil (1930-1945)". Revista Brasileira de história São Paulo 36.71 (2016): 1-25. Web. 21 jul. 2019. 